\title{
Inovação pedagógica na abordagem teórico-metodológica da temática Ecologia Médica no currículo do curso de graduação em medicina
}

\section{Pedagogical innovation in theoretical and methodological approach to thematic Medical Ecology course curriculum in undergraduate medical}

\author{
${ }^{1}$ Maria Cristina Almeida de Souza \\ ${ }^{1}$ Marcos Antônio Mendonça \\ ${ }^{1}$ Elisa Maria Amorim da Costa \\ ${ }^{1}$ José Carlos Dantas Teixeira \\ 1 João Carlos de Souza Côrtes Júnior \\ ${ }^{1}$ Sebastião Jorge da Cunha Gonçalves \\ ${ }^{1}$ Eduardo Herrera Rodrigues Almeida Júnior
}

\section{RESUMO}

Este artigo, um estudo descritivo, relata a adoção de inovação pedagógica na abordagem teórico-metodológica da temática Ecologia Médica no curso de graduação em medicina da Universidade Severino Sombra (USS) por meio do conteúdo programático da disciplina Sistema de Integração Curricular e Comunitária I (SICC I). Tendo por estratégia pedagógica a problematização da realidade observada na comunidade com consequente protagonismo discente no processo de aprendizagem, a adoção da inovação resultou na graduação de médicos com visão ampliada de saúde, conscientes da interface entre a saúde e o meio ambiente, e da relevância da intersetorialidade para a resolutividade da atenção em saúde prestada à população. Pedagogicamente concluiu-se que a temática Ecologia Médica constitui elemento integrador, transversal e longitudinal de conteúdos curriculares, não só entre disciplinas do curso de medicina, mas também com programas disciplinares de outras áreas do saber e que sua sistematização contribuiu para o atendimento às Diretrizes Curriculares Nacionais para os cursos de graduação em medicina.

Palavras-chave: Educação Médica, Meio Ambiente, Educação Ambiental 
This article is a descriptive study and reports the adoption of pedagogical innovation in theoretical-methodological approach about Medical Ecology in graduate course of medicine at the University Severino Sombra (USS) through the syllabus of the discipline of Curriculum Integration and Community System I (I SICC). This pedagogical resource for the observation of the community by the student with consequent role of the student in the learning process, the adoption of innovation has resulted in the graduation of professionals with expanded vision of health conscious interface between health and the environment, and the relevance of intersectoral approach to solving the health care provided to the population. Pedagogically it was concluded that the topic Medical Ecology is responsable by the integration, transverse and longitudinal, of the component of curricula, not only between disciplines of medical school, but also disciplinary programs with other areas of knowledge and its systematization contributed to meeting the Curriculum Guidelines nationals for undergraduate courses in medicine.

Key-words: Medical Education, Environment, Environmental Education

\section{INTRODUÇÃO}

Ecologia Médica (EM), Medicina Ecológica ou Ecomedicina são terminologias utilizadas para definir um ramo da medicina que estuda a relação existente entre os fatores ambientais e os de saúde (ALMEIDA, 2012). Lobo (2012) coloca a EM como sinônimo de Medicina Ambiental e Ecologia Celular, cujos objetivos principais são restaurar o equilíbrio entre o homem e a natureza e tratar as patologias ocasionadas pela perda desse equilíbrio.

Segundo Pelicioni (2005) grande parte dos agravos em saúde se relaciona com problemas ambientais, uma vez que as alterações no meio ambiente interferem na saúde e na qualidade de vida das pessoas, de forma que meio ambiente e saúde são indissociáveis.

A conferência sobre Atenção Primária à Saúde (APS), organizada pela Organização Mundial de Saúde (OMS) em Alma-Ata, na antiga União das Repúblicas Socialistas Soviéticas (URSS), em setembro de 1978, estreou o conceito de "Saúde para Todos", convocando todos os países a revisarem seus sistemas de saúde, tornando-os acessíveis à população, como direito básico do cidadão. O conceito de APS foi definido nessa conferência, entendo-se a atenção como essencial à saúde, baseada num modelo prático e científico que possui métodos e tecnologias universalmente acessíveis a pessoas e famílias dentro das comunidades, sendo o primeiro nível de contato do indivíduo com o sistema de saúde e condição essencial para o desenvolvimento socioeconômico da comunidade (RONCOLETTA, 2010).

Para a resolutividade da assistência em saúde, em todos os níveis de atenção, é imprescindível que os profissionais se atentem aos determinantes ambientais do processo saúde-doença (PSD). Para tanto, se faz necessário que, ainda como alunos de graduação, os médicos percebam que a degradação ambiental está diretamente associada à deterioração das condições sociais nas quais se produzem e se propagam novas epidemias (SENA et al., 2010).

A formação desse profissional exige que os cursos de graduação adotem projetos pedagógicos em consonância com as Diretrizes Curriculares Nacionais para os cursos de graduação em medicina (DCN) (Brasil, 2014), que orientam para formação de médicos generalistas, aptos a assistir integralmente o ser humano. A busca pela implementação de uma mudança para adequar a formação profissional à diversidade e complexidade do mundo contemporâneo implica o enfrentamento de desafios como o afastamento das práticas de ensino centradas no educa- 
dor em detrimento de atividades de aprendizagem centradas no educando, o abandono da concepção de saúde como ausência de doença na direção do entendimento de saúde enquanto condições de vida, o rompimento da polarização individual/coletivo e biológico/social para uma consideração de interpenetração e transversalidade.

Atualmente a formação em medicina passa por uma crise, na qual a visão biologicista predominante e a fragmentação do saber médico têm acarretado pouca consideração à subjetividade e cultura do doente. Tal crise tem impulsionado movimentos de mudança para o resgate de uma medicina que contemple o processo saúdedoença, abordando o ser humano nas dimensões biopsicossociais (RONCOLETTA, 2010).

Contudo, apesar das mudanças curriculares, o modelo de formação profissional ainda apresenta foco em técnicas e práticas não preventivas. Isto evidencia o distanciamento das estratégias de ações preventivas e de educação em saúde, reforçando as especializações fragmentárias e inviabilizando o uso adequado de recursos e o aproveitamento da qualificação profissional. Quanto à questão ambiental, concebida como fator de grande importância para o desenvolvimento humano, parece que na prática profissional não vêm ocupando posição de tanta relevância em estudos que associem estratégias de promoção de saúde na relação entre homem e ambiente (PEREIRA et al., 2012).

O curso de graduação em medicina da Universidade Severino Sombra (USS), no município de Vassouras, na região centro sul do Estado do Rio de Janeiro, ao incluir a Ecologia Médica entre os temas transversais de programas disciplinares, sistematizou sua abordagem no currículo, adotando uma prática pedagógica viabilizadora da interdisciplinaridade entre saúde e ambiente.

O objetivo desse artigo é relatar a experiência com a abordagem teórico-metodológica da EM no currículo do curso de graduação em medicina da USS, enfocando os aspectos pedagógicos advindos com a inovação e suas contribuições para a formação de médicos com visão ampliada de saúde, conscientes da interface entre saúde e meio ambiente.

\section{A EXPERIÊNCIA CONTEXTUALIZADA E A METODOLOGIA APLICADA}

Às margens do rio Paraíba do Sul e da rodovia BR 393, entrecortado pelos trilhos da rede ferroviária, na periferia do município de Vassouras, na região centro sul do Estado do Rio de Janeiro, se localiza o bairro Ipiranga onde residem aproximadamente 300 famílias, totalizando cerca de 800 pessoas, que embora disponham de equipamentos sociais como Unidade Estratégia Saúde da Família (ESF) e Escola Municipalizada, enfrentam as adversidades decorrentes de suas precárias condições socioeconômicas e dos impactos ambientais decorrentes da instalação no local de uma empresa de laminados de aço (SOUZA et al., 2014).

Nesse contexto percebeu-se a necessidade de atuação dos alunos do curso de medicina da USS, em parceria com os de Engenharia Ambiental e Sanitária, na realização de ações de promoção da saúde dos moradores por meio de ações relacionadas à questão ambiental e de saúde. As ações planejadas estão contempladas no programa da disciplina "Sistema de Integração Curricular Comunitária I" (SICC I), alocada no $1^{\circ}$. período da matriz curricular do curso de medicina, com carga da quatro horas semanais, das quais $50 \%$ está destinada às atividades práticas na comunidade.

Previamente ao início das atividades, as lideranças comunitárias são contactadas para verificarem sua viabilidade e proporem os ajustes necessários, de modo que coletivamente construídas, tais atividades possam contribuir para a qualidade de vida dos moradores tanto quanto para a graduação de médicos e engenheiros atentos à relação entre os determinantes ambientais e o processo saúde-doença e cônscios da relevância das políticas intersetoriais para a promoção da qualidade de vida das pessoas.

Como estratégia pedagógica, o conteúdo teórico da disciplina SICC I é dividido em dois momentos. No primeiro, realizado previamente ao desenvolvimento das atividades na comunidade, abordam-se em sala de aula 
temáticas imprescindíveis à construção de referencial teórico pelo aluno: práticas de gerenciamento de resíduos sólidos, vigilância ambiental, Lei 8.080/90, Lei 8.142/90, intersetorialidade, sustentabilidade, epidemiologia de doenças prevalentes na região, orientações sobre Visita Domiciliar (VD) e abordagem familiar. Posteriormente, no segundo momento, problematiza-se a realidade observada na comunidade por meio de Metodologias Ativas de Aprendizagem (MAA), que contribuem para o aprimoramento da autonomia intelectual e senso crítico dos alunos, protagonistas do processo de ensino-aprendizagem. As MAA utilizam a problematização como estratégia de ensino-aprendizagem, com objetivo de alcançar e motivar o discente pois diante do problema, ele se detém, examina, reflete, relaciona a sua historia e passa a ressignificar suas descobertas. Para otimizar a observação da realidade vista na comunidade, os alunos do $1^{\circ}$. período atuam em conjunto com os do $2^{\circ}$. e do $3^{\circ}$., cujas atividades estão relacionadas ao programa das disciplinas SICC II e III, que respectivamente alocadas no $2^{\circ}$. e $3^{\circ}$. período do curso, também são desenvolvidas no bairro de modo a ser ter um cenário de prática acadêmica com distintas oportunidades de aprendizagem. Dessa forma, para a abordagem familiar e atuação na comunidade são compostos grupos integrados por um aluno de cada um dos três primeiros períodos do curso de medicina e alunos de engenharia ambiental e sanitária a fim de estimular a troca mútua de saberes. Denominados G4, esses grupos atuam sob a orientação e supervisão de professores facilitadores e se responsabilizam pelas ações de educação ambiental e assistência em saúde às famílias previamente cadastradas e cujos integrantes concordaram em participar das atividades.

No G4 os alunos desempenham funções previamente determinadas. Assim, ao aluno do $3^{\circ}$. período compete a execução daquelas relacionadas à assistência básica em saúde, como aferir sinais vitais e registrar dados antropométricos; ao do $2^{\circ}$. período cabe o planejamento e a realização de atividades de educação em saúde, cuja temática é programada de acordo com as demandas locais e inclui a troca de informações com o moradores contribuindo para o desenvolvimento do autocuidado em saúde e também da consciência ambiental, tanto da comunidade como dos alunos. Sob a responsabilidade dos alunos do $1^{\circ}$. período dos cursos de medicina e medicina veterinária estão a coleta de dados e o registro informações para construção do diagnóstico das condições ambientais da família.

Estrategicamente ao aluno do $1^{\circ}$. período é disponibilizado um questionário estruturado sobre as temáticas zoonoses e saneamento básico - instrumento integrante da pesquisa "Perfil sócio demográfico e condições de saúde de famílias residentes nos bairros Ipiranga e Itakamosi, em Vassouras/RJ”, aprovada pelo Comitê de Ética em Pesquisa da USS em 14/06/2013 (Parecer 308.142 - CAAE 15973913.6.0000.5290) - para ser respondido individualmente pelos integrantes da família. Também lhe é solicitada a realização de fotografias do entorno da residência da família, dentro dos limites internos da propriedade, a fim de registrar a presença de vetores em seus criadouros e de nichos ecológicos, possível contaminação do solo e/ou do rio Paraíba do Sul, que representa zona limítrofe com quintais de algumas moradias. Silva e Soares (2012) utilizaram imagens fotográficas como estratégia para a abordagem de diversas faces de um contexto ambiental.

Nesta experiência, constatou-se o observado por Ianni e Quitério (2006) acerca da necessidade de que o aluno do curso de graduação perceba a imprescindibilidade da atuação do profissional de saúde na identificação das ações intersetoriais necessárias à promoção de saúde das pessoas assistidas e que a resolutividade da atenção em saúde está diretamente relacionada à solução de demandas que envolvam outros setores da municipalidade, além da saúde. Importante que o aluno compreenda que a saúde se realiza em larga medida, fora do setor saúde, em áreas das atividades humanas nem sempre alcançáveis pelos mecanismos e estratégias tradicionais de prevenção e regulação. A promoção de saúde propõe que intervenções e diagnósticos devam emergir de processos que pressuponham interdisciplinaridade e intersetorialidade.

Ao final do semestre letivo, os aluno do $1^{\circ}$. período de medicina e medicina veterinária, integrantes do G4, elaboram um relatório com a condição ambiental observada na comunidade, no qual está inclusa uma proposta de intervenção que contenha medidas preventivas e corretivas possíveis de implementação. Também ao final período acadêmico, com o intuito de dar visibilidade às atividades desenvolvidas pelos alunos em relação à interface saúde/ambiente, as fotografias são expostas na Biblioteca Central da USS no evento “Luz, câmera, ação: Ipiranga em exposição!”. 
Como parte do processo avaliativo dos acadêmicos, além da análise da ficha de auto-avaliação discente, do registro da assiduidade, interesse, postura proativa na busca por soluções para resolução dos problemas identificados, o acadêmico é avaliado também por meio de um Portfólio Reflexivo, elaborado ao longo do semestre, contendo seu diário de campo, o material elaborado e utilizado para desenvolver as ações educativas, além das reflexões sobre o aprendizado construído. O portfólio como instrumento de reflexão crítica sobre a prática evidencia potencialidades e fragilidades no processo de condução do ensino e nas vivências em campo.

\section{DISCUSSÃO}

Historicamente a formação dos profissionais de saúde tem sido pautada no uso de metodologias conservadores, sob forte influencia do mecanicismo da inspiração cartesiana, fragmentado e reducionista (CAPRA, 2006).

O Brasil vive uma oportunidade única para debater a formação médica e evoluir no modelo de assistência em saúde. Esse novo modelo exige mudanças no tipo de formação (PADILHA, 2004), que vêm sendo discutida por vários movimentos - Integração Docente Assistencial (IDA), Cinaem (Comissão Interinstitucional para Avaliação do Ensino Médico), Projetos Uni, Pet-Saúde (Programa de Educação pelo Trabalho) (PONTES et al., 2006).

Para exercer uma prática médica em consonância com os princípios e diretrizes do Sistema Único de Saúde (SUS), as instituições de ensino superior vêm atendendo às Diretrizes Curriculares Nacionais para os cursos de graduação em medicina (DCN) (Brasil, 2014), que preconizam a graduação de médico generalista apto a assistir a população de forma integral e resolutiva, em todos os níveis de complexidade da atenção em saúde. A realização dessa atenção e assistência à população demanda por ações de promoção e de recuperação de saúde, prevenção às doenças e também por atividades de educação em saúde que abordem a Ecologia Médica.

Assim, se faz necessário graduar médicos e veterinários capazes de atuar no processo saúde-doença (PSD), desde a identificação dos seus determinantes até a elaboração da proposta terapêutica adequada ao caso. Entre os determinantes do PSD estão as condições ambientais inseridas no contexto de vida da população. Assim, é imprescindível que os futuros profissionais de saúde construam conhecimento acerca da relação direta entre o meio ambiente e o adoecimento, otimizando a resolutividade da atenção e da assistência prestada. Uma das maneiras de se construir este conhecimento é através da Ecologia Médica (EM). É fundamental, portanto, a sistematização desta temática nos currículos dos cursos de graduação na área de saúde, em especial em medicina.

Destarte, o estudo da interação dos pacientes com o ambiente poderá contribuir para o redirecionamento da educação médica baseado no que é necessário para a população, promovendo uma adequação dos cenários de aprendizagem e do conteúdo curricular (RONCOLETTA, 2010). Esta proposta de inovação pedagógica almeja se contrapor ao constatado por Morin (1997) de que a educação acabou ensinando as pessoas a separarem os fatos ao invés de interligarem o conhecimento produzidos nos diferentes campos do saber.

As ações na comunidade permitem que o aluno observe que, em alguns casos, os sintomas de determinada doença estão diretamente relacionados à questão ambiental, cabendo-lhes portanto, atuar também na causa do agravo concomitantemente à intervenção terapêutica. $\mathrm{O}$ aluno percebe a necessidade de conhecer o contexto e as condições de vida das famílias pelo profissional de saúde que deseja verdadeiramente, contribuir para o bem estar daquelas pessoas. E também que muitas vezes uma VD é tão importante quanto uma consulta ambulatorial.

Durante a aplicação do questionário sobre zoonoses pelo aluno, observou-se o citado por Gandolfo et al., 2010, de que na ida a campo, o pesquisador não apenas compila e coleta dados, mas também cria espaço de diálogo em que sujeito e objeto de pesquisa se confundem, ocorrendo uma troca de experiências em ambos os sentidos. Esse espaço tem o potencial de estabelecer contatos que aproximam o pesquisador do pesquisado e o conhecimento acadêmico daquele construído socialmente. Essa atividade contribui para que o acadêmico 
aprimore a capacidade de comunicação, imprescindível para o estreitamento dos vínculos entre o profissional e o paciente e para o exercício da prática profissional.

Importante que os resultados da pesquisa retornem à comunidade, inicialmente por meio das lideranças comunitárias, que de posse dessas informações, se empoderam e consequentemente, fortalecem o controle social de modo a planejarem e proporem aos gestores públicos ações de intervenção capazes de minimizar ou eliminar os problemas ambientais detectados pelos alunos. Essa questão é problematizada em sala de aula, contribuindo para que o aluno compreenda que, mesmo indiretamente, suas ações na comunidade contribuem para o fortalecimento do controle social nas políticas públicas.

A exposição de fotografias realizadas pelos alunos em espaço de uso coletivo pelos universitários, somatiza a divulgação da contribuição social da USS à comunidade do bairro Ipiranga e a difusão entre os gestores acadêmicos dos demais cursos da área da saúde, acerca da imprescindibilidade de abordar a temática EM nos currículos. Esta exposição funciona como estratégia de motivação e orgulho para os alunos cujas fotografias foram expostas e otimiza a sistematização do projeto.

De acordo com Penna (1999) em um mundo onde a necessidade humana de valorizar-se e ser respeitado pelos seus semelhantes manifestam-se de forma crescente, por meio do consumismo e de compra de bens supérfluos, torna-se difícil desenvolver um pensamento crítico e reflexivo em relação à questão socioambiental nas pessoas pertencentes às elites tanto urbanas quanto rurais. A sociedade ainda valoriza os bens materiais, a beleza física das pessoas, o modismo em detrimento dos valores culturais, científicos e morais. Talvez mais complexo seja ainda promover a compreensão e apreensão de tais valores em pessoas pertencentes às classes inferiores, pois é difícil falarmos de sociedade sustentável em um país onde a miséria e a fome ainda estão presentes (Manucci, 2004), o que ajuda a compreender as razões da posição reacionária de alguns moradores em participar do projeto.

\section{CONCLUSÕES}

Se faz necessário o desenvolvimento de ações, pelos profissionais de saúde, de promoção da saúde e de qualidade de vida para a população e também para a prevenção de enfermidades associadas ao meio ambiente. Com conhecimentos alicerçados na Ecologia Médica, esses profissionais poderão orientar a população acerca da adoção de medidas do controle dos fatores de risco às doenças relacionadas à questão ambiental. Os autores desse artigo constataram que as atividades dos alunos na comunidade representa uma experiência diferenciada, especialmente por tratar-se de vivência que exige trabalho coletivo, participativo e crítico-reflexivo, tendo em vista as necessidades de saúde da população. Nesse contexto, a abordagem da Ecologia Médica torna-se imprescindível para a graduação de futuros médicos conscientes da relação direta entre saúde e meio ambiente no processo de adoecimento. Os autores acreditam na viabilidade da abordagem descrita neste artigo como estratégia para o ensino contextualizado da temática Ecologia Médica no ensino médico.

Os profissionais de saúde necessitam estar preparados para uma análise crítica dos desafios apresentados na área da Ecologia Médica para que sejam agentes de mudanças e transformações na saúde, no meio ambiente e, consequentemente na prevenção de doenças.

Como desdobramentos pedagógicos advindos com a adoção da inovação, constatou-se que a sistematização curricular do tema EM contribuiu para a integração disciplinar, para mudança da cultura de avaliação, para otimização do uso de metodologia que priorizam o uso de MAA em detrimento da aula expositiva, centrada no professor.

Ressalta-se que é também mérito dessa iniciativa a contribuição para uma prática pedagógica ética, crítica, reflexiva e transformadora. 


\section{REFERÊNCIAS}

ALMEIDA, C. Entenda o que significa ecologia médica. Disponível em < http://noticias.uol.com.br/ciencia/ ultimas-noticias/redacao/2010/09/10/entenda-o-que-significa-ecologia-medica.htm>. Acesso em 14/04/2014.

CAPRA, F. A teia da vida - uma nova compreensão científica dos sistema vivos. São Paulo: Cultrix, 1996.

BRASIL. Ministério da Educação. Diretrizes Curriculares Nacionais para os Cursos de Graduação em Medicina. Resolução n. 3,0 d e03/06/2014. Disponível em https://www.google.com.br/webhp?sourceid=chromeinstant\&rlz=1C1NNVC_enBR494BR494\&ion=1\&espv=2\&ie=UTF-8\#q=Diretrizes\%20Curriculares\%20 Nacionais\%20para\%20os\%20Cursos\%20de\%20Gradua\%C3\%A7\%C3\%A30\%20em\%20Medicina\%202014.

GANDOLFO, E.S.; UYSSÉA, M.A.; SILVA, S.D.M.; LACERDA, V.D.; HAMAZAKI, N. A etnobiologia como zona de convergência entre ensino, pesquisa e extensão. In: GUIMARÃES, L.B.; KRELLING, A.G.; BARCELOS, V. (org). Tecendo a educação ambiental na arena cultural. p. 139-158. Petrópolis: DP et Alii, 2010.

IANNI, A.M.Z.; QUITÉRIO, L.A.D. A questão ambiental urbana no Programa Saúde da Família: avaliação da estratégia ambiental numa política pública de saúde. Ambiente \& Sociedade, v. IX, n.1, p.169-180 jan./jun., 2006.

LOBO, F. Ecologia Médica, Ortomolecular e Mineralograma. O que é Ecologia Médica. Disponível em < http://www.ecologiamedica.net/2011/10/ecologia-medica-ortomolecular-e.html>. Acesso em 01/03/2014.

MANUCCI, M. Sociedade sustentável. In: HAMMES, U.S. Proposta metodológica de macroeducação. 2.ed. p 25-28, São Paulo: Globo, 2004.

MORIN, E. Complexidade e ética na solidariedade. In: CASTRO, G.; CARVALHO, E.A.; ALMEIDA, M.C. Ensaios de complexidade. Porto Alegre: Sulina, 1997. p. 15-24.

PADILHA, R.Q. Muito além da importação de médicos. Jornal O Globo. 18/04/2014. p. 17.

PELICIONI, M.C.F. Promoção da saúde e meio ambiente: uma trajetória técnico-política. In: PHILIPPI JUNIOR, A.; PELICIONI, M.C.F. Educação Ambiental e Sustentabilidade. p. 413-420. Barueri: Manole; 2005. (Coleção ambiental, n.3).

PENNA, C.G. O Estado do Planeta: sociedade de consumo e degradação ambiental. Rio de Janeiro: Record, 1999.

PEREIRA, C.A.R.; MELO, J.V., FERNANDES, A.L.T. A educação ambiental como estratégia da Atenção Primária à Saúde. Rev Bras med fam comunidade, v.3,n.7, p. 108-116, 2012.

PONTES, A.L.; REGO, S.; SILVA JUNIOR, A.G.S. Saber e prática docente na transformação do ensino médico. Rev Bras Educ Méd., v.2, n.30, p. 66-75, 2006.

RONCOLETTA, A.F.T. Ecologia médica: uma reavaliação na realidade brasileira, 2010. Tese (doutorado). Faculdade de Medicina USP. Saão Pualo, 2010.

SENA, J.; CEZAR-VAZ, M.R.; BONOW C.A.; FIGUEIREDO, P.P.; COSTA, V.Z. Uma prática pedagógica através das racionalidades socioambientais: um ensaio teórico da formação do enfermeiro. Texto Contexto Enferm, v.3, n. 19, p. 570-7, jul./set., 2010.

SILVA, M.B.C.; SOARES, R.A.R. Ensino de meio ambiente: uma questão de contextualização? Revista Praxis. Ano IV, n.7, jan. 2012, p.55-59.

SOUZA, M.C.A. de.; MENDONÇA, M.A.; COSTA, E.M.A.; GONÇALVES, S.J.C.; TEIXEIRA, J.C.D.; ALMEIDA JÚNIOR, E.H.R.; CÔRTES JÚNIOR, J.C.S. O Universitário Transformador na comunidade: a experiência da USS! Rev Bras Educ Méd., v.38, n.2, 269-274, abr./jun. 2014. 